BMJ Open

Diabetes

Research

\& Care

\title{
Opinions of vascular surgeons and podiatrists in Australia and New Zealand on the use of hyperbaric oxygen therapy for lower limb ulcers
}

\author{
Aaron Drovandi (D) , ${ }^{1}$ Malindu E Fernando, ${ }^{1}$ Tejas P Singh, ${ }^{1}$ Torres Woolley, ${ }^{2}$ \\ Jonathan Golledge (D) 1,3
}

To cite: Drovandi A Fernando ME, Singh TP, et al. Opinions of vascular surgeons and podiatrists in Australia and New Zealand on the use of hyperbaric oxygen therapy for lower limb ulcers. BMJ Open Diab Res Care 2020;8:e001590. doi:10.1136/ bmjdrc-2020-001590

\section{- Additional material is} published online only. To view please visit the journal online (http://dx.doi.org/10.1136/ bmjdrc-2020-001590).

Received 18 May 2020 Revised 18 June 2020 Accepted 27 June 2020
Check for updates

\section{(C) Author(s) (or their} employer(s)) 2020. Re-use permitted under CC BY-NC. No commercial re-use. See rights and permissions. Published by BMJ.

For numbered affiliations see end of article.

\section{Correspondence to}

Professor Jonathan Golledge; jonathan.golledge@jcu.edu.au

\section{ABSTRACT}

Introduction Hyperbaric oxygen therapy (HBOT) has been suggested to improve healing of lower limb ulcers, though the quality of available evidence is weak to moderate. This study assessed the opinions and use of HBOT by specialists treating lower limb ulcers.

Research design and methods Accredited vascular surgeons and podiatrists in Australia and New Zealand were sent an online survey via their professional organizations. The survey asked about their use and opinions of HBOT in treating lower limb ischemic, neuropathic and venous ulcers. Data were summarized with descriptive statistics. Non-parametric tests were used to compare survey results obtained from vascular surgeons and podiatrists.

Results 61 vascular surgeons and 40 podiatrists completed the survey. Thirty-seven specialists used HBOT for treating lower limb ulcers, with the remainder indicating they did not feel there was a role for HBOT $(n=25)$ or did not have access to HBOT $(n=39)$. Less than $8 \%$ of specialists indicated that HBOT frequently or always had a role in treating ischemic, neuropathic or venous ulcers. Compared with podiatrists, vascular surgeons were significantly less likely to indicate HBOT had a treatment role for any ulcer type $(p<0.001, p=0.004$, and $p<0.001$, respectively), though significantly more likely to indicate they currently used HBOT for treating lower limb ulcers $(p<0.001)$. Most specialists $(n=76)$ believed that a large clinical trial is needed to determine the efficacy of HBOT in treating lower limb ulcers.

Conclusions Vascular surgeons and podiatrists do not feel HBOT has a frequent role in treating lower limb ulcers, but do feel there needs to be a large clinical trial to test its value.

\section{INTRODUCTION}

Lower limb ulcers, which are usually caused by neuropathy, venous or arterial disease, are an important cause of reduced health-related quality of life, increased risk of amputation and high healthcare costs. ${ }^{1-4}$ Established treatments for lower limb ulcers include compression bandaging, off-loading of high foot pressures and venous or arterial surgery, depending on the etiology of the ulcer. ${ }^{5}$ Not

\section{Significance of this study}

What is already known about this subject?

- Hyperbaric oxygen therapy (HBOT) is recommended for the treatment of non-healing lower limb ulcers, though the quality of evidence supporting this recommendation is low to moderate, and the opinion of specialists who use this therapy is poorly understood.

\section{What are the new findings?}

- Vascular surgeons and podiatrists in Australia and New Zealand indicated that they perceive HBOT as having an infrequent role in the management of nonhealing venous, ischemic, and neuropathic ulcers.

How might these results change the focus of research or clinical practice?

- Well-designed clinical trials are needed to provide high-quality evidence to inform on the appropriate use of HBOT for lower limb ulcer management among vascular surgeons and podiatrists.

infrequently, these treatments fail to heal the ulcer, requiring additional therapies to prevent poor outcomes, such as major amputation. ${ }^{2-467}$ Hyperbaric oxygen therapy (HBOT) is a potential treatment option for lower limb ulcers. It is believed to promote healing by facilitating tissue oxygenation, promoting angiogenesis, and stimulating an effective immune response to aid control of infection. ${ }^{8} 9$ There is, however, ongoing debate on the effectiveness and indications for HBOT in treating lower limb ulcers. ${ }^{10} 11$

A recent meta-analysis of nine randomized trials reported that HBOT improved the odds of healing lower limb ulcers in people with diabetes. ${ }^{12}$ There were however methodological weaknesses identified in most of the trials, such as a lack of sample size calculations and absence of blinding outcome assessments to group allocation. ${ }^{12}$ There was also substantial 
heterogeneity in the findings. ${ }^{12}$ There was an uncharacteristically strong benefit of HBOT in one of the included trials and when this trial was removed from analyses this substantially reduced the benefit of HBOT. ${ }^{12}{ }^{13}$ The most recent randomized trial reported that HBOT did not improve ulcer healing or reduce amputations. ${ }^{14}$ The provision of HBOT is expensive, time consuming, inconvenient for patients (especially those living in rural areas), and has reported complications, ${ }^{15}$ such as barotrauma ${ }^{16}$ which must be considered when making decisions about its use. Despite these contrasting findings, current international guidelines recommend the use of HBOT for non-healing lower limb ulcers, ${ }^{5} 71718$ while acknowledging that the evidence of benefit is only weak to moderate.

The aim of this study was to obtain opinions from two types of specialists about their use and perceptions of the role of HBOT in treating lower limb ulcers. Vascular surgeons and podiatrists were the specialists selected for this study, since these are two of the main specialties that manage lower limb ulcers, and may refer patients for HBOT in their practice.

\section{PARTICIPANTS AND METHODS}

Study design and participant recruitment

This was a cross-sectional study in which an online survey run through SurveyMonkey was distributed to vascular surgeons and podiatrists in Australia and New Zealand between August 2019 and March 2020. In these two countries, HBOT is funded for treating non-healing lower limb ulcers at public hospitals. Multiple organizations expected to have vascular surgeons or podiatrists as members were approached via email and requested to distribute the survey link. The organizations contacted were the Australia and New Zealand Society for Vascular Surgery, Diabetic Foot Australia, the Australian Wound Management Association, the Australian Diabetes Society, the New Zealand Ministry of Health, the Podiatry Board of Australia and Podiatry New Zealand. The initial request was sent in August 2019, with reminder requests sent in December 2019 and February 2020.

\section{Procedure and data items collected}

Specialists were first presented with an information and consent screen which outlined the purpose of the survey, including the abstract from a recent meta-analysis examining the efficacy of HBOT for treating lower limb ulcers. ${ }^{12}$ After consenting to participate, specialists were asked where their practice was located and their specialty. They were then asked whether they currently used HBOT in the treatment of lower limb ulcers and presented with statements related to their perceived role of HBOT in the treatment of ischemic, neuropathic or venous ulcers, which they rated on 5-point ordinal scales (never, rarely, sometimes, frequently or always). The final questions in the survey related to their access to HBOT facilities, criteria for HBOT therapy and the perceived need for more evidence on HBOT effectiveness. The full survey is shown in online supplementary material. In pilot testing, the survey took less than 5 min to complete. There were no incentives offered for participation.

\section{Data analysis}

To be considered a complete survey, specialists must have completed a minimum of the first seven survey questions (online supplementary material). These questions covered their opinion on the treatment role of HBOT for the three ulcer types and whether or not they used HBOT for treating lower limb ulcers in their practice. A descriptive analysis was conducted to determine the characteristics of the participants and sum their responses. The 5-point ordinal scale ratings (never, rarely, sometimes, frequently, always) in response to the statements on perceived HBOT role for each ulcer type were scored as 1-5 respectively. These data were presented as median (IQR) and the responses of vascular surgeons and podiatrists compared using Mann-Whitney U test in SPSS V.25 $(\mathrm{IBM}){ }^{19}$

\section{RESULTS}

\section{Participants}

A total of 102 survey responses were received from 61 vascular surgeons and 41 podiatrists, with 101 responses from 61 vascular surgeons and 40 podiatrists considered complete. Most specialists were practicing in the states of Queensland $(n=41)$, New South Wales $(n=20)$ or Victoria $(n=15)$. Between one and seven respondents were practicing in each of the other Australian states and territories and 12 specialists (eight vascular surgeons and four podiatrists) were practicing in New Zealand.

\section{Current use of HBOT for lower limb ulcers}

Thirty-seven (36.6\%) specialists indicated they currently used HBOT for the treatment of lower limb ulcers. The other specialists indicated that they did not feel there was a role for HBOT $(\mathrm{n}=25 ; 24.8 \%)$, or that they did not have access to HBOT $(\mathrm{n}=39 ; 38.6 \%)$. Most of those without HBOT access indicated that the resource simply had not been established in their practice setting $(n=23 ; 22.7 \%)$, was too expensive $(n=6 ; 5.9 \%)$, or was not felt to be beneficial to the hospital $(n=4 ; 4.0 \%)$. Responses provided in open-text comment boxes included: 'Only some patients were able to travel for regular treatment' (Podiatrist), 'Not enough evidence to suggest HBOT is effective' (Podiatrist), 'None in my town. I do refer the occasional one but most patients not willing to travel' (Vascular surgeon), and 'Limited use for the cost' (Vascular surgeon).

\section{Responses to statements about the role of HBOT for treating} different types of ulcers

Only $8(7.9 \%), 6(5.9 \%)$ and $2(2.0 \%)$ of the specialists indicated that HBOT 'frequently' or 'always' had a role in the treatment of ischemic, neuropathic and venous lower limb ulcers, respectively (table 1 ). In comparison, 43 (42.6\%), 27 (26.7\%) and $24(23.8 \%)$ specialists 
Table 1 Responses to statements about the role of hyperbaric oxygen therapy in treating different types of lower limb ulcers $(\mathrm{n}=101)$

\begin{tabular}{|c|c|c|c|c|c|c|}
\hline Statement & Never & Rarely & Sometimes & Frequently & Always & Median (IQR) \\
\hline HBOT has a treatment role in ischemic foot ulcers. & $13(13)$ & $37(37)$ & $43(43)$ & $7(7)$ & $1(1)$ & $3(2-4)$ \\
\hline HBOT has a treatment role in neuropathic foot ulcers. & $24(24)$ & $44(44)$ & $27(27)$ & $5(5)$ & $1(1)$ & $2(1-3)$ \\
\hline HBOT has a treatment role in venous leg ulcers. & $29(29)$ & $46(46)$ & $24(24)$ & $1(1)$ & $1(1)$ & $2(1-3)$ \\
\hline
\end{tabular}

Data were presented as $\mathrm{n}(\%)$ and median (IQR).

HBOT, hyperbaric oxygen therapy.

indicated HBOT 'sometimes' had a role in the treatment of ischemic, neuropathic and venous lower limb ulcers, respectively (table 1 ). The remainder responded that HBOT 'rarely' or 'never' had a role in treating these ulcers (table 1).

\section{Comparison of responses between vascular surgeons and podiatrists}

Vascular surgeons were significantly less likely than podiatrists to indicate that HBOT frequently or always had a role in the treatment of ischemic, neuropathic and venous lower limb ulcers $(\mathrm{p}<0.001$ for ischemic lower limb ulcers, $\mathrm{p}=0.004$ for neuropathic lower limb ulcers, and $\mathrm{p}<0.001$ for venous lower limb ulcers) (table 2).

\section{Criteria for HBOT use}

More than half $(31 ; 50.8 \%)$ of vascular surgeons compared with only six $(15 \%)$ podiatrists indicated that they currently used HBOT for treating lower limb ulcers $(\mathrm{p}<0.001) \quad$ (table 3$)$. For specialists who used HBOT for treating lower limb ulcers $(\mathrm{n}=37 ; 36.6 \%)$, a lack of response to other therapies, such as revascularization, wound debridement, dressing and pressure off-loading, was most frequently cited as a criterion for patient selection (table 3). Free-text responses included:

Table 2 Comparison between vascular surgeons and podiatrists' perceptions on hyperbaric oxygen therapy $(n=101)$

\begin{tabular}{|c|c|c|}
\hline Question/statement & $\begin{array}{l}\text { Specialist-specific } \\
\text { responses } \\
\text { 5-point ordinal } \\
\text { scale-median (IQR) }\end{array}$ & $P$ value \\
\hline \multirow{2}{*}{$\begin{array}{l}\text { HBOT has a treatment } \\
\text { role in ischemic foot } \\
\text { ulcers. }\end{array}$} & $\begin{array}{l}\text { Vascular surgeons: } 2 \\
(1-3)\end{array}$ & \multirow[t]{2}{*}{$<0.001$} \\
\hline & Podiatrists: 3 (2-4) & \\
\hline \multirow{2}{*}{$\begin{array}{l}\text { HBOT has a treatment } \\
\text { role in neuropathic foot } \\
\text { ulcers. }\end{array}$} & $\begin{array}{l}\text { Vascular surgeons: } 2 \\
(1-3)\end{array}$ & \multirow[t]{2}{*}{0.004} \\
\hline & Podiatrists: 3 (2-4) & \\
\hline \multirow[t]{2}{*}{$\begin{array}{l}\text { HBOT has a treatment } \\
\text { role in venous leg ulcers. }\end{array}$} & $\begin{array}{l}\text { Vascular surgeons: } 2 \\
(1-3)\end{array}$ & \multirow[t]{2}{*}{$<0.001$} \\
\hline & Podiatrists: 2 (1-3) & \\
\hline
\end{tabular}

Data were presented as $\mathrm{n}(\%)$ and median response (IQR). Mann-Whitney $U$ test was used to compare specialist opinions.

HBOT, hyperbaric oxygen therapy.
'After debridement or drainage of mid-foot sepsis without macrovascular arterial compromise' (Vascular surgeon), 'Post-revascularisation' (Podiatrist), 'Ulcers sometimes defy conventional categorization, e.g. ulcers over the Achilles tendon that have local ischaemic even when blood supply to the foot is good. These do well with HBOT (Vascular surgeon). Transcutaneous oxygen pressures $\left(\mathrm{TcPO}_{\mathrm{g}}\right)(\mathrm{n}=33 ; 32.7 \%)$ and ineligibility for other therapies $(\mathrm{n}=15 ; 14.9 \%)$ were also commonly cited as criteria for HBOT. 'I ask the HBOT unit to determine $\mathrm{TcPO}_{2}$ to determine chance of benefit' (Vascular surgeon).

\section{Need for further randomized clinical trials}

The vast majority of respondents $(\mathrm{n}=76 ; 75 \%)$ indicated that a large trial was needed to test the efficacy of HBOT in treating lower limb ulcers. The remainder believed that no trial was needed either due to strong evidence for this therapy $(\mathrm{n}=4 ; 4.0 \%)$, strong evidence against this therapy $(\mathrm{n}=5 ; 5.0 \%)$, or a belief that HBOT will never be an appropriate therapy $(n=3 ; 3.0 \%)$. There were no significant differences in these responses between vascular surgeons and podiatrists.

\section{DISCUSSION}

This study investigated the opinions of vascular surgeons and podiatrists on the use of HBOT for lower limb ulcers. One-third of specialists completing this survey indicated that they actively use HBOT for ischemic, neuropathic, or venous leg ulcers, with few indicating it had a strong role in treatment for any of these ulcer types. Vascular surgeons were more likely to have access to and use HBOT, whereas podiatrists felt that it had a stronger role in treatment. When choosing HBOT as a treatment for these ulcers, a lack of response to other therapies and low $\mathrm{TcPO}_{2}$ were considered key criteria. Most specialists indicated that a large clinical trial was needed to assess the efficacy of HBOT in treating these ulcers. Overall, this study indicates the lack of high-quality evidence which supports the use of HBOT in managing lower limb ulcers, as reflected by the low number of specialists indicating that they use it frequently for ulcer management.

International guidelines ${ }^{5} 71718$ 20-23 refer to several recent reviews ${ }^{10} 1824$ and notable randomized controlled trials $^{1425-28}$ on HBOT efficacy in ulcer management. A number of these systematic reviews including the most recent ${ }^{12}$ have found that HBOT increases the proportion 
Table 3 Specialist use of and selection criteria for hyperbaric oxygen therapy

\begin{tabular}{|c|c|c|}
\hline Question/statement & Specialist responses & n (\%) \\
\hline \multirow{6}{*}{$\begin{array}{l}\text { Do you currently use HBOT for } \\
\text { treating lower limb ulcers? }\end{array}$} & Vascular surgeons $(n=61)$ & \\
\hline & Yes & $31(31)$ \\
\hline & No & $30(30)$ \\
\hline & Podiatrists $(n=40)$ & \\
\hline & Yes & $6(6)$ \\
\hline & No & $34(34)$ \\
\hline \multirow{3}{*}{$\begin{array}{l}\text { If you use HBOT for lower limb } \\
\text { ulcers, how do you select patients } \\
\text { for treatment? (select all that apply) }\end{array}$} & Transcutaneous oxygen pressure & $19(51)$ \\
\hline & Not suited to other therapies & $9(24)$ \\
\hline & Lack of response to other therapies & $22(60)$ \\
\hline \multirow{15}{*}{$\begin{array}{l}\text { I use HBOT for lower limb ulcers } \\
\text { based on: (select all that apply) }\end{array}$} & $\mathrm{TcPO}_{2}$ level less than $20 \mathrm{~mm} \mathrm{Hg}$ & $8(22)$ \\
\hline & $\mathrm{TcPO}_{2}$ level less than $40 \mathrm{~mm} \mathrm{Hg}$ & $12(32)$ \\
\hline & $\mathrm{TcPO}_{2}$ level less than $50 \mathrm{~mm} \mathrm{Hg}$ & $4(11)$ \\
\hline & Another $\mathrm{TcPO}_{2}$ level to that described above & $3(8.1$ \\
\hline & Not healing after a period of other therapy for 4 weeks & $6(16)$ \\
\hline & Not healing after a period of other therapy for 8 weeks & $9(24)$ \\
\hline & Not healing after a period of other therapy for 12 weeks & $13(35)$ \\
\hline & Not healing after a period of other therapy for 6 months & $9(24)$ \\
\hline & Not healing after a period of other therapy for $>6$ months & $10(27)$ \\
\hline & Lack of response to wound debridement & $13(35)$ \\
\hline & Lack of response to negative pressure wound therapy & $14(38)$ \\
\hline & Lack of response to regular wound dressings & $18(49)$ \\
\hline & Lack of response to pressure off-loading & $16(43)$ \\
\hline & Lack of response to revascularization & $30(81)$ \\
\hline & $\begin{array}{l}\text { Oxygen challenge test with increased } \mathrm{TcPO}_{2} \text { to }>100 \mathrm{~mm} \mathrm{Hg} \text { in the } \\
\text { chamber }\end{array}$ & $11(30)$ \\
\hline
\end{tabular}

$\mathrm{HBOT}$, hyperbaric oxygen therapy; $\mathrm{TCPO}_{2}$, transcutaneous oxygen pressure.

of ulcers that completely heal and reduces the incidence of major and minor amputations. Thus, current guidelines recommend HBOT is considered for non-healing lower limb ulcers. It is noted, however, that prior clinical trials have had conflicting findings and methodological shortcomings, highlighting the need for further welldesigned trials to provide reliable guidance, which was also indicated by specialists in the current survey. Most of the current guidelines recommend HBOT for ulcer healing either in conjunction with standard therapy, ${ }^{17}$ or only when standard therapy has failed to heal the ulcer in a reasonable amount of time, ${ }^{57182022}$ which in most trials is considered as after 4 weeks of therapy. ${ }^{12}$ Vascular surgeons and podiatrists in this study reported that these were the directions that they most frequently followed when using HBOT. They indicated that they also considered HBOT when patients were not eligible for standard therapy and also used $\mathrm{TcPO}_{2}$ to guide use of HBOT, which is not listed in current guidelines. ${ }^{5} 71718$ 20-23

The reasons behind the variation between vascular surgeon and podiatrist in the use of HBOT and opinions about the value of HBOT in ulcer healing identified in this study are not certain. Vascular surgeons typically work in tertiary hospitals where HBOT facilities are usually located, making it likely they have greater access to refer patients for this therapy than podiatrists, who more frequently work in community clinics. This may explain why vascular surgeons more frequently indicated that they refer patients for HBOT than podiatrists, despite their opinions of it having a less frequent place in therapy. The reasons for this difference in opinions on the treatment role of HBOT may be due to variations in professional guidelines, reflecting ulcer etiology commonly managed by these specialists. The current international guideline published for vascular surgeons states that there is ongoing controversy about the value of HBOT for treating lower limb ulcers. ${ }^{5}$ The guidelines state that there may be a role for the use of HBOT to accelerate ulcer healing in people with diabetes with non-healing neuropathic ulcers and lowgrade ischemia. ${ }^{5}$ This is in comparison to multiple Australian guidelines used by podiatrists, which appear to be more supportive for the use of HBOT, stating it may be considered as part of a comprehensive wound management program. ${ }^{29} 30$ 
As a result of the aforementioned shortcomings in previous research, there is widespread consensus on the need for further research investigating the benefit (if any) of HBOT in ulcer healing, ${ }^{21}{ }^{23}$ which was indicated by the majority of vascular surgeons and podiatrists in this study. This further research in the form of a well-powered randomized controlled trial would need to demonstrate a clear benefit of HBOT in ulcer wound healing through a methodologically sound approach that avoids shortcomings demonstrated in previous research. The outcomes of such a trial would inform guideline recommendations to direct a range of relevant health professionals, including vascular surgeons and podiatrists, on the appropriateness and efficacy of HBOT in lower limb ulcer management.

The current study has a number of limitations that should be acknowledged. As the surveys were sent out to practitioners via professional societies, it was not possible to calculate the response rate. It is therefore unclear how representative the opinions obtained were of the overall community of vascular surgeons and podiatrists in Australia and New Zealand. Also, only two types of specialists who may refer patients for HBOT were included in this survey. Their opinions may differ from other relevant specialists, such as general practitioners, nurses and hyperbaric oxygen specialists. Lastly, only specialists from two countries were included in this survey. Their opinions may differ from specialists in other countries.

In conclusion, this survey suggests that approximately one-third of Australia and New Zealand vascular surgeons and podiatrists use HBOT in treating lower limb ulcers. These specialists mostly felt that HBOT only sometimes had a role in treating ischemic, neuropathic, or venous lower limb ulcers. A majority of specialists indicated that further high-quality research was needed to guide the use of this therapy and determine its effectiveness for ulcer management.

\section{Author affiliations \\ ${ }^{1}$ Queensland Research Centre for Peripheral Vascular Disease, James Cook University College of Medicine and Dentistry, Townsville, Queensland, Australia ${ }^{2}$ College of Medicine and Dentistry, James Cook University Division of Tropical Health and Medicine, Townsville, Queensland, Australia \\ ${ }^{3}$ Department of Vascular and Endovascular Surgery, Townsville University Hospital, Townsville, Queensland, Australia}

Acknowledgements The authors thank the participating vascular surgeons and podiatrists and the professional organizations who assisted in the completion of this survey.

Contributors JG takes responsibility for the integrity of the work as a whole, from inception to published article. JG and TPS designed the research study. JG, TPS, MEF, and TW designed the survey tool. JG, MEF, and AD collected and analyzed the data. JG, MEF, and AD wrote the manuscript, with all authors editing and approving the final manuscript version.

Funding Funding from The Townsville Hospital and Health Services Study, Education and Research Trust Fund, James Cook University (Strategic Research Investment Fund) and Queensland Government supported this work. JG holds a Practitioner Fellowship from the National Health and Medical Research Council (1117061) and a Senior Clinical Research Fellowship from the Queensland Government, Australia.
Disclaimer The funders played no role in study design, conduct, data collection, analysis and interpretation, and did not assist in preparation or review of this manuscript.

Competing interests None declared.

Patient consent for publication Not required.

Ethics approval This study received an ethics waiver from the Townsville Hospital and Health Service Human Research Ethics Committee (LNR/2019/QTHS/54813). Ethics waivers are available for clinical audits and quality improvement or assurance research activities that are considered as being of low or negligible risk.

Provenance and peer review Not commissioned; externally peer reviewed.

Data availability statement Data are available upon reasonable request to the authors.

Open access This is an open access article distributed in accordance with the Creative Commons Attribution Non Commercial (CC BY-NC 4.0) license, which permits others to distribute, remix, adapt, build upon this work non-commercially, and license their derivative works on different terms, provided the original work is properly cited, appropriate credit is given, any changes made indicated, and the use is non-commercial. See: http://creativecommons.org/licenses/by-nc/4.0/.

ORCID iDs

Aaron Drovandi http://orcid.org/0000-0002-8682-1218

Jonathan Golledge http://orcid.org/0000-0002-5779-8848

\section{REFERENCES}

1 Olsson M, Järbrink K, Divakar U, et al. The humanistic and economic burden of chronic wounds: a systematic review. Wound Repair Regen 2019;27:114-25.

2 Frykberg RG, Banks J. Challenges in the treatment of chronic wounds. Adv Wound Care 2015;4:560-82.

3 Han G, Ceilley R. Chronic wound healing: a review of current management and treatments. Adv Ther 2017:34:599-610.

4 Choa R, Rayatt S, Mahtani K. Marjolin's ulcer. BMJ 2015;351:h3997.

5 Conte MS, Bradbury AW, Kolh P, et al. Global vascular guidelines on the management of chronic limb-threatening ischemia. Eur $J$ Vasc Endovasc Surg 2019;58:S1-109.

6 O'Meara S, Cullum N, Nelson EA, et al. Compression for venous leg ulcers. Cochrane Database Syst Rev 2012;11:CD000265.

7 Rayman G, Vas P, Dhatariya K, et al. Guidelines on use of interventions to enhance healing of chronic foot ulcers in diabetes (IWGDF 2019 update). Diabetes Metab Res Rev 2020;36 Suppl $1: \mathrm{e} 3283$.

8 Camporesi EM, Bosco G. Mechanisms of action of hyperbaric oxygen therapy. Undersea Hyperb Med 2014;41:247-52.

9 Hicks CW, Selvarajah S, Mathioudakis N, et al. Burden of Infected Diabetic Foot Ulcers on Hospital Admissions and Costs. Ann Vasc Surg 2016;33:149-58.

10 Kranke P, Bennett MH, Martyn-St James M, et al. Hyperbaric oxygen therapy for chronic wounds. Cochrane Database Syst Rev 2015;28:CD004123.

11 Zhao D, Luo S, Xu W, et al. Efficacy and safety of hyperbaric oxygen therapy used in patients with diabetic foot: a meta-analysis of randomized clinical trials. Clin Ther 2017;39:2088-94.

12 Golledge J, Singh TP. Systematic review and meta-analysis of clinical trials examining the effect of hyperbaric oxygen therapy in people with diabetes-related lower limb ulcers. Diabet Med 2019;36:813-26.

13 Duzgun AP, Satır HZ, Ozozan O, et al. Effect of hyperbaric oxygen therapy on healing of diabetic foot ulcers. J Foot Ankle Surg 2008; $47: 515-9$

14 Santema KTB, Stoekenbroek RM, Koelemay MJW, et al. Hyperbaric Oxygen Therapy in the Treatment of Ischemic Lower- Extremity Ulcers in Patients With Diabetes: Results of the DAMO ${ }_{2}$ CLES Multicenter Randomized Clinical Trial. Diabetes Care 2018;41:112-9.

15 Chuck AW, Hailey D, Jacobs P, et al. Cost-Effectiveness and budget impact of adjunctive hyperbaric oxygen therapy for diabetic foot ulcers. Int J Technol Assess Health Care 2008;24:178-83.

16 Lalieu RC, Brouwer RJ, Ubbink DT, et al. Hyperbaric oxygen therapy for nonischemic diabetic ulcers: a systematic review. Wound Repair Regen 2020;28:266-75.

17 Health Service Executive,. Republic of Ireland. HSE national wound management guidelines, 2018. Available: https://healthservice.hse. ie/filelibrary/onmsd/hse-wound-management-guidelines-2018.pdf

18 American Diabetes Association. 11. Microvascular Complications and Foot Care: Standards of Medical Care in Diabetes-2019. Diabetes Care 2019;42:S124-38. 
19 Boone HN, Boone DA. Analyzing likert data. J Ex 2012;50:1-5.

20 Huang ET, Mansouri J, Murad MH, et al. A clinical practice guideline for the use of hyperbaric oxygen therapy in the treatment of diabetic foot ulcers. Undersea Hyperb Med 2015;42:205-47.

21 Gerhard-Herman MD, Gornik HL, Barrett C, et al. 2016 AHA/ACC guideline on the management of patients with lower extremity peripheral artery disease: a report of the American College of Cardiology/American heart association Task force on clinical practice guidelines. J Am Coll Cardiol 2017;69:e71-126.

22 Crawford PE, Fields-Varnado M, WOCN Society. Guideline for the management of wounds in patients with lower-extremity neuropathic disease: an executive summary. J Wound Ostomy Continence Nurs 2013;40:34-45.

23 Lipsky BA, Berendt AR, Cornia PB, et al. 2012 infectious diseases Society of America clinical practice guideline for the diagnosis and treatment of diabetic foot infections. Clin Infect Dis 2012;54:e132-73.

24 Game FL, Apelqvist J, Attinger C, et al. Effectiveness of interventions to enhance healing of chronic ulcers of the foot in diabetes: a systematic review. Diabetes Metab Res Rev 2016;32 Suppl 1:154-68.
25 Health Quality Ontario. Hyperbaric oxygen therapy for the treatment of diabetic foot ulcers: a health technology assessment. Ont Health Technol Assess Ser 2017;17:1.

26 Löndahl M, Katzman P, Nilsson A, et al. Hyperbaric oxygen therapy facilitates healing of chronic foot ulcers in patients with diabetes. Diabetes Care 2010;33:998-1003.

27 Elraiyah T, Tsapas A, Prutsky G, et al. A systematic review and metaanalysis of adjunctive therapies in diabetic foot ulcers. J Vasc Surg 2016;63:46S-58.

28 Fedorko L, Bowen JM, Jones W, et al. Hyperbaric oxygen therapy does not reduce indications for amputation in patients with diabetes with nonhealing ulcers of the lower limb: a prospective, double-blind, randomized controlled clinical trial. Diabetes Care 2016;39:392-9

29 Abidia A, Laden G, Kuhan G, et al. The role of hyperbaric oxygen therapy in ischaemic diabetic lower extremity ulcers: a doubleblind randomised-controlled trial. Eur J Vasc Endovasc Surg 2003;25:513-8.

30 Diabetic Foot Australia. Australian and international guidelines on diabetic foot disease, 2016. Available: https://diabeticfootaustralia. org/wp-content/uploads/DFA-Guides-you-through-guidelines.pdf 